\section{BACKGROUND}

- The early diagnostic in patients with clinical findings of meningitis is still challenging. Our aim is to determine the epidemiological characteristics in a series of children diagnosed with meningitis in a tertiary hospital in southern Spain

\section{METHODS}

Retrospective descriptive study of children treated in the Emergency Department during the years 2014-2017, with diagnosis of meningitis confirmed by biochemistry, culture or PCR in cerebrospinal fluid

\section{Distribution by sex (\%)}

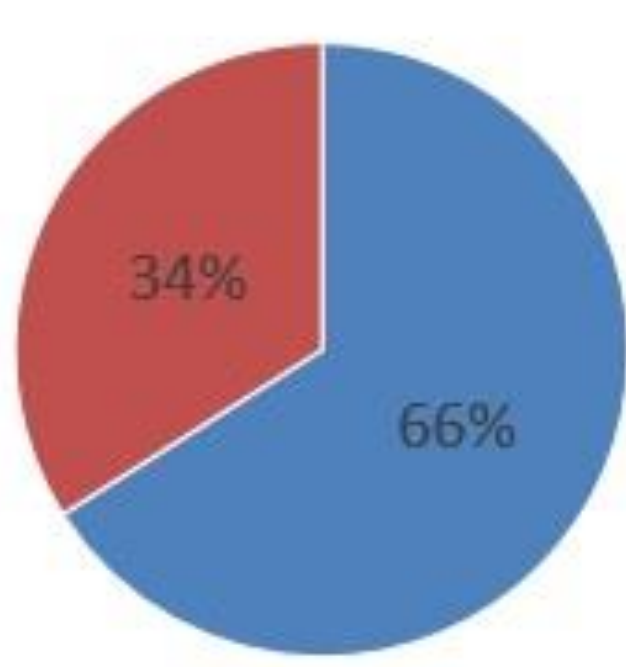

- Males — Women

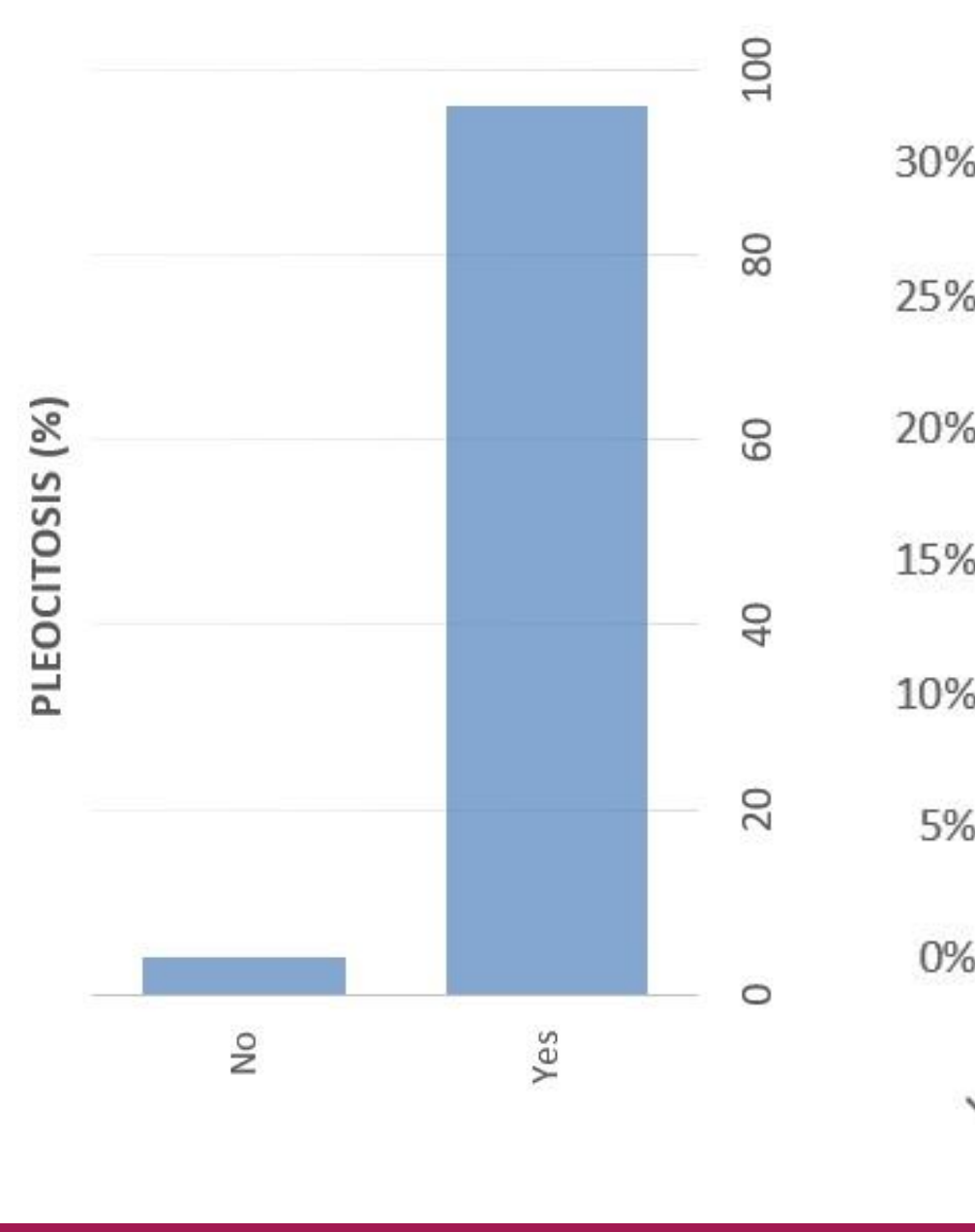

(1) Hospital La Paz, Pediatric Infectious Diseases, Madrid, Spain. (2) Hospital de Poniente, Pediatric Infectious Diseases, El Ejido, Spain

Median data in CSF (mg/dl) 120 60 40 20 0$$
\text { Glucose }
$$
Enterovirus meningitis

Distrubution by month (\%)

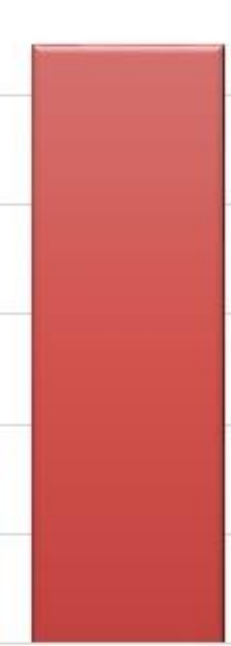

Proteins Bacterial meningitis

Predominant cells in CSF

\title{
Bacterial meningitis
}

Enterovirus meningitis

- Mononuclear cells

- Polymorphonuclear cells

DISTRIBUTION BY GERMS

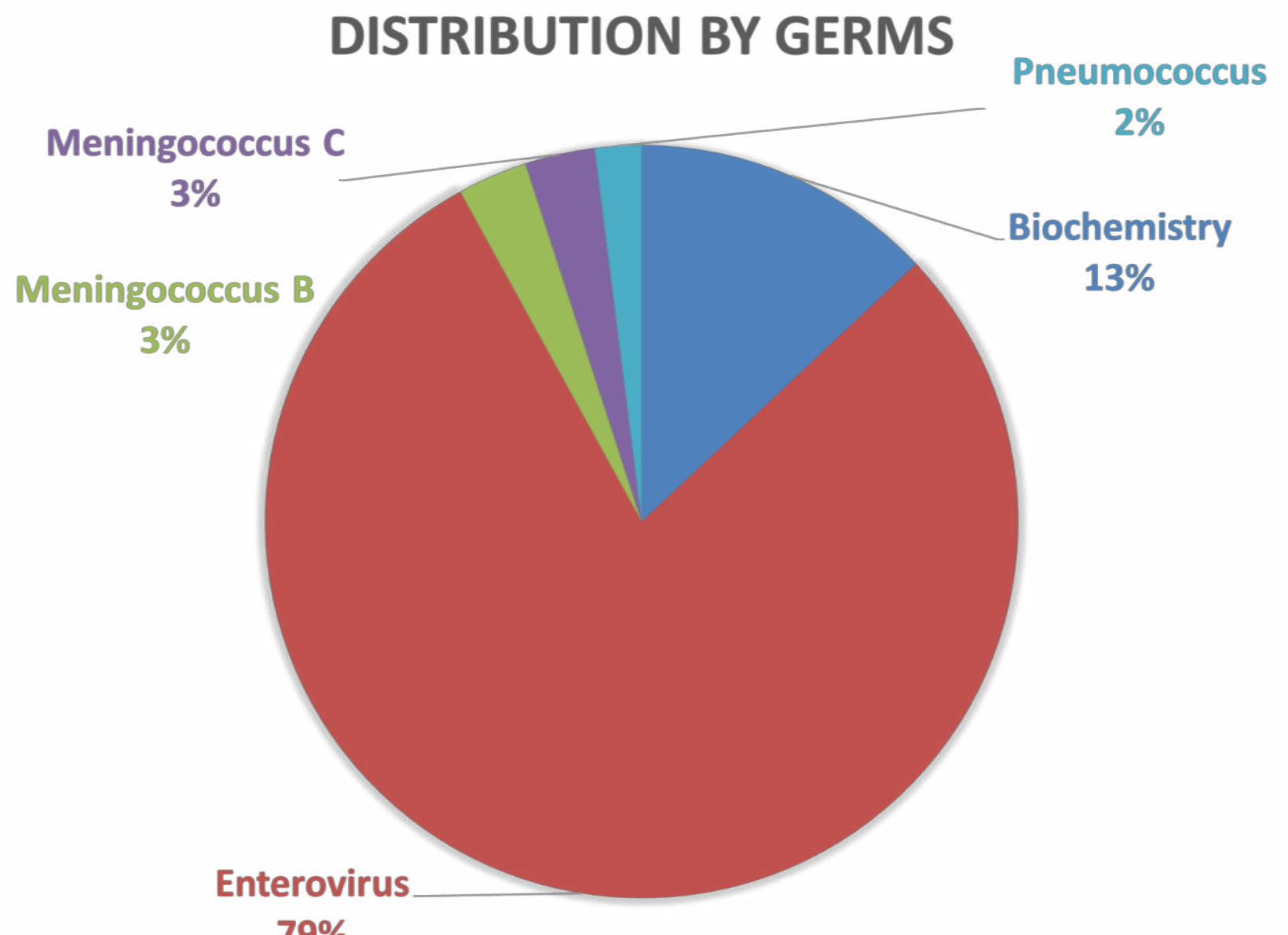

\section{RESULTS}

A total sample of 62 cases is presented. According to sex: males $66 \% ; 34 \%$ women; By age: median in 6 years. Laboratory data: Pleocitosis: positive in $96 \%$ of the cases; in the remaining $4 \%$ no pleocistosis was found, resulting this latest ones positive for enterovirus. Predominant cells: in enterovirus meningitis, mononuclear cells predominated in $66 \%$ of the cases, while polymorphonuclear cells predominated in the remaining $33 \%$. In contrast, in bacteria caused, polymorphonuclear predominated in $100 \%$. The median of the glucose and proteins in the CSF in the group caused by enterovirus was 64 and $35 \mathrm{mg} / \mathrm{dl}$, while in the group caused by bacteria was 54 and $109 \mathrm{mg} / \mathrm{dl}$ respectively. Germs were confirmed only by biochemistry $13 \%$, enterovirus $79 \%$, meningococcus $B 3 \%$, meningococcus C $3 \%$, pneumococcus $2 \%$.

\section{DISCUSSION}

Most of the meningitis in the pediatric age are caused by enteroviruses, generally occuring in the spring, as reflected in our series. The median age and the predominance of the male sex also coincide with what is described in the literature. In $33 \%$ of the cases caused by enteroviral infection, a polymorphonuclear predominance can be observed in the biochemical analysis of the CSF which probably leads to an increasing use of antibiotic therapy. Furthermore, we highlight cases produced by meningococcus $\mathrm{C}$ all occurring in unvaccinated patients 